\title{
N-Type Conductive Ultrananocrystalline Diamond Films Grown by Hot Filament CVD
}

\author{
Institute of Micro and Nanomaterials, Ulm University, 89081 Ulm, Germany \\ Correspondence should be addressed to Michael Mertens; michael.mertens@uni-ulm.de \\ and Markus Mohr; markus.mohr@uni-ulm.de
}

Michael Mertens, Markus Mohr, Neda Wiora, Kai Brühne, and Hans-Jörg Fecht

Received 24 September 2014; Revised 20 January 2015; Accepted 12 February 2015

Academic Editor: Aiying Wang

Copyright (C) 2015 Michael Mertens et al. This is an open access article distributed under the Creative Commons Attribution License, which permits unrestricted use, distribution, and reproduction in any medium, provided the original work is properly cited.

\begin{abstract}
We present the synthesis of ultrananocrystalline diamond (UNCD) films by application of hot filament chemical vapor deposition (HFCVD). We furthermore studied the different morphological, structural, and electrical properties. The grown films are fine grained with grain sizes between 4 and $7 \mathrm{~nm}$. The UNCD films exhibit different electrical conductivities, dependent on grain boundary structure. We present different contact metallizations exhibiting ohmic contact behavior and good adhesion to the UNCD surface. The temperature dependence of the electrical conductivity is presented between -200 and $900^{\circ} \mathrm{C}$. We furthermore present spectroscopic investigations of the films, supporting that the origin of the conductivity is the structure and volume of the grain boundary.
\end{abstract}

\section{Introduction}

Electronic and microelectromechanic sensor devices built from diamond have already been demonstrated [1-4]. However, one of the main obstacles to make use of diamond as a material for electronic applications is the difficulty of doping diamond [5]. Diamond can be p-doped by boron, even though the acceptor level of boron is $0.37 \mathrm{eV}$ over the valence band [6] and is therefore not activated at room temperature. By increasing the doping level, the activation energy decreases, so that p-doped diamond can be thermally activated at room temperature [7]. In contrast to that, no shallow donors were found for diamond [5].

An interesting, novel kind of n-type conductivity, present at room temperature, which could fill this gap, was found in ultrananocrystalline diamond films [8-10]. The addition of nitrogen (which has activation energy of $1.7 \mathrm{eV}$, if incorporated substitutionally [5]) can lead in ultrananocrystalline diamond films to a high electrical conductivity at room temperature [8-10]. In [11] it was shown that the incorporation of nitrogen in grain boundaries leads to additional localized states within the band gap. Birrell et al. [12] have produced similar films by plasma CVD and conclude that the addition of nitrogen does lead to an increased width of a $s p^{2}$-carbon grain boundary phase. In contrast to our findings [10], they reach an increasing conductivity for an increased addition of nitrogen [12].

Investigations of Ikeda et al. [13], who also used plasma CVD for deposition of UNCD films with nitrogen addition, show that the increase of ordering and amount of a $s p^{2}$ carbon grain boundary phase is more responsible for an increasing conduction than the concentration of incorporated nitrogen.

In contrast to most of the published work on conductive UNCD films, where the films are mostly grown by plasma CVD, we present the growth of UNCD films by hot filament chemical vapor deposition (HFCVD).

We show that, by increase of substrate temperature, a strong change in morphology and an increase of electrical conductivity of the films take place.

\section{Experiments}

The UNCD films were grown by using the hot filament chemical vapor deposition (HFCVD) technique.

This highly flexible and scalable technique allows growing diamond films on different substrates like silicon, quartz, and 


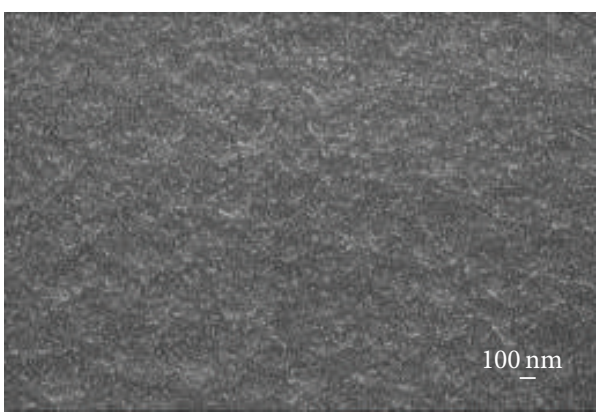

(a)

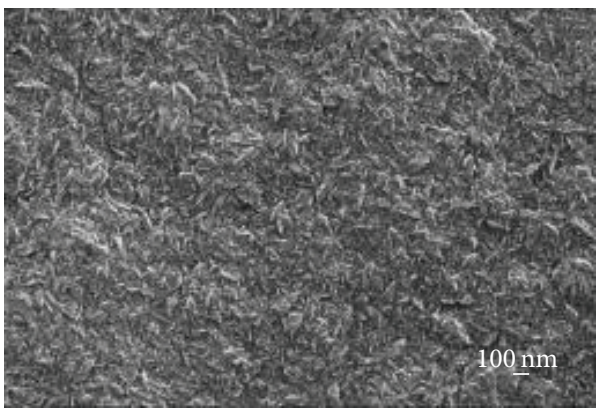

(c)

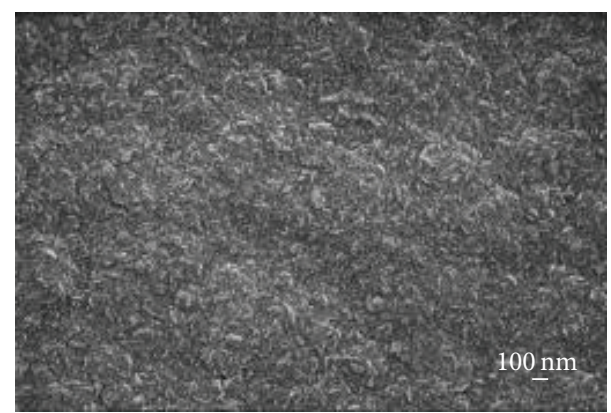

(b)

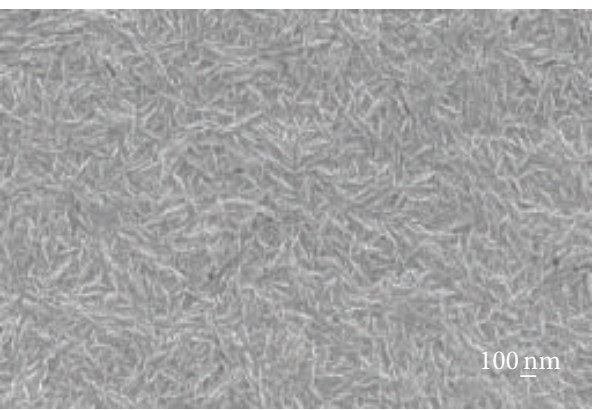

(d)

FIGURE 1: Influence of the substrate temperature on the morphology of the UNCD films is shown in the SEM pictures (a) ca. $570^{\circ} \mathrm{C}$, (b) and (c) $580^{\circ} \mathrm{C}-630^{\circ} \mathrm{C}$, and (d) ca. $750^{\circ} \mathrm{C}$.

carbide forming metals. Also coating of structured and three dimensional substrates is possible [1].

Before growth, the substrates were pretreated by ultrasonication in a nanodiamond solution. By this treatment, small seed crystals are deposited on the substrate with a density in the order of $10^{11} \mathrm{~cm}^{-2}$ [2]. This procedure, in contrast to bias enhanced nucleation, opens the possibility to grow diamond on some nonconductive substrates [2].

We used tungsten filaments that were electrically heated up to about $2000^{\circ} \mathrm{C}$. The used gas, maintained during growth, was a methane/hydrogen mixture $\left(5 \% \mathrm{CH}_{4} / \mathrm{H}_{2}\right)$. Additionally we introduced different amounts of ammonia (between $0.35 \%$ and $\left.3.5 \% \mathrm{NH}_{3} / \mathrm{H}_{2}\right)$. We investigate the influence of extra gas addition (ammonia) on the electrical conductivity of the grown films. The influence of ammonia addition on the morphology was already shown in [10].

Conductive UNCD films were grown on 3 inches, $\langle 100\rangle$ silicon wafer with a $300 \mathrm{~nm}$ silicon oxide layer deposited by PECVD for an electrical insulation between the substrate and the conductive film. Due to the high seeding density, a closed film is achieved after a few minutes and the silicon oxide is exposed to atomic hydrogen for only short time.

Figure 1 shows microstructures of different UNCD films grown with different substrate temperatures. The substrate temperature can be influenced indirectly by different filament currents and by the distance of substrate to filament or directly by using a sample holder at a cooling and heating system.

Different substrate temperatures are leading to completely different microstructures. Figure 1(a) presents a very

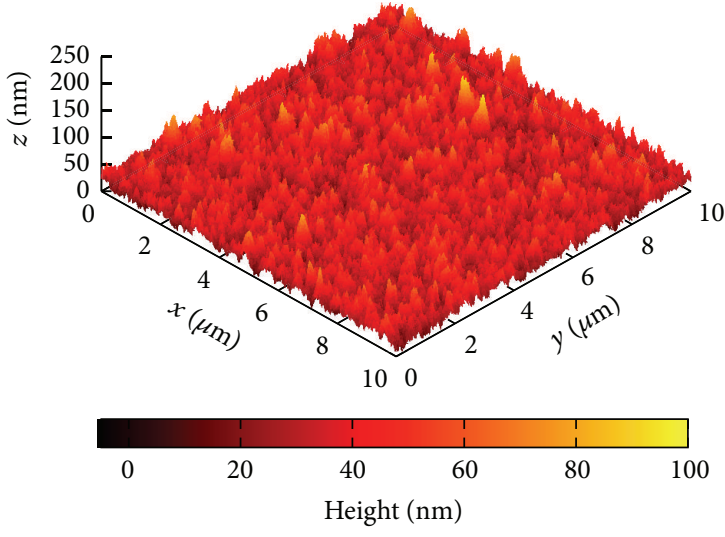

FIGURE 2: AFM measurement of $1 \mu \mathrm{m}$ thick UNCD film on silicon substrate (compare SEM in Figure 1(a)).

homogeneous microstructure, grown at a substrate temperature of about $570^{\circ} \mathrm{C}$. With increasing substrate temperature, from $580^{\circ} \mathrm{C}$ to $630^{\circ} \mathrm{C}$, like exemplarily shown in Figures 1(b) and 1(c), more and more cluster-like structures are visible in the microstructure. Above about $700^{\circ} \mathrm{C}$ substrate temperature the diamond microstructure changes completely to another structure, which is shown in Figure 1(d).

The surface roughness measured by atomic force microscopy (AFM) for all grown films is about $10 \mathrm{~nm}$ (RMS). A representative measurement is shown in Figure 2.

$\mathrm{X}$-ray diffraction (XRD) measurements were performed, proofing that the film consists of crystalline diamond grains. 


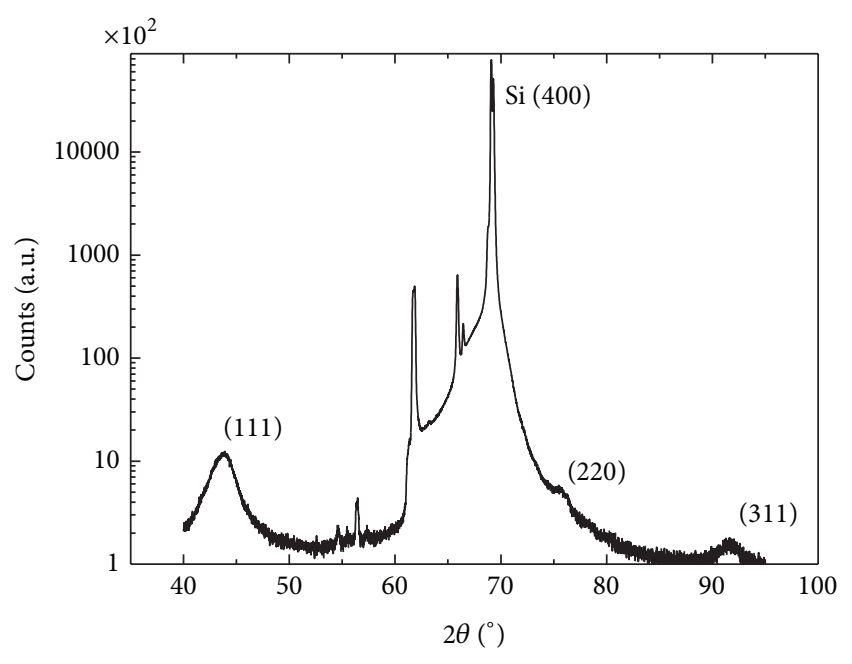

FIGURE 3: XRD measurement with copper anode (1.5444 $\AA$ ) on a $1 \mu \mathrm{m}$ thick UNCD film, with average grain size of $5 \mathrm{~nm}$.

In Figure 3, a typical measurement for an UNCD film is presented.

The measurement was done using a standard BraggBrentano geometry and a $\mathrm{Cu} \mathrm{K} \alpha \mathrm{X}$-ray source. The three diamond peaks at $2 \theta=43.9^{\circ}$ (111), $75.2^{\circ}(220)$, and $91.4^{\circ}$ (311) are clearly detectable. The $\langle 100\rangle$ orientated silicon substrate leads to a peak at $69^{\circ}$ and additionally some small peaks on the left side of the silicon (400) peak are detected, caused by the not perfectly monochromatic X-ray source.

The average grain size is in the range of 4 to $6 \mathrm{~nm}$, as measured by XRD. The full width at half maximum of the (111) peak was fitted and the grain size was determined by applying Scherrer's equation.

To further analyze the grown films, texture measurements were done. In order to obtain pole figures for the (111) peak, the $\theta$ and $2 \theta$ angles were kept constant at $\theta=21.95^{\circ}$ and $2 \theta=43.9^{\circ}$. Then the sample was rotated around its surface normal and, for each rotation angle $\phi$, the intensities were measured. Furthermore, the sample was tilted against the beam and detector plane and for each tilt angle $\psi$ the diffraction intensities are recorded. The measured pole figure of the (111) peak is presented in Figure 4. Peaks at a tilt angle of $\psi=35^{\circ}$ would indicate a (110) fiber texture; a sharp peak at tilt angle $\psi=0^{\circ}$ would indicate a (111) texture.

This measurement shows that the grains in our UNCD films (which were grown thinner than $2 \mu$ m only) have no significant preferred orientations.

2.1. Electrical Characterization. The specific resistivity of different UNCD microstructures was measured by using the Van-der-Pauw method. Therefore, clearly defined rectangular geometries were etched out of the diamond film. Furthermore, ohmic metal contacts ( $\mathrm{Ti}$ adhesion layer and $\mathrm{Au}$ ) were deposited by using sputtering. The specific resistivity reaches values from $1 \times 10^{3} \Omega \mathrm{cm}$ up to $5 \times 10^{-3} \Omega \mathrm{cm}$ on highly conductive samples.

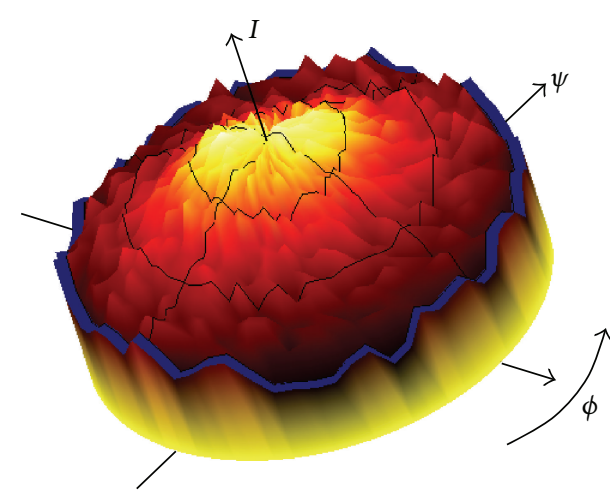

FIgURE 4: Pole figure of the (111) peak.

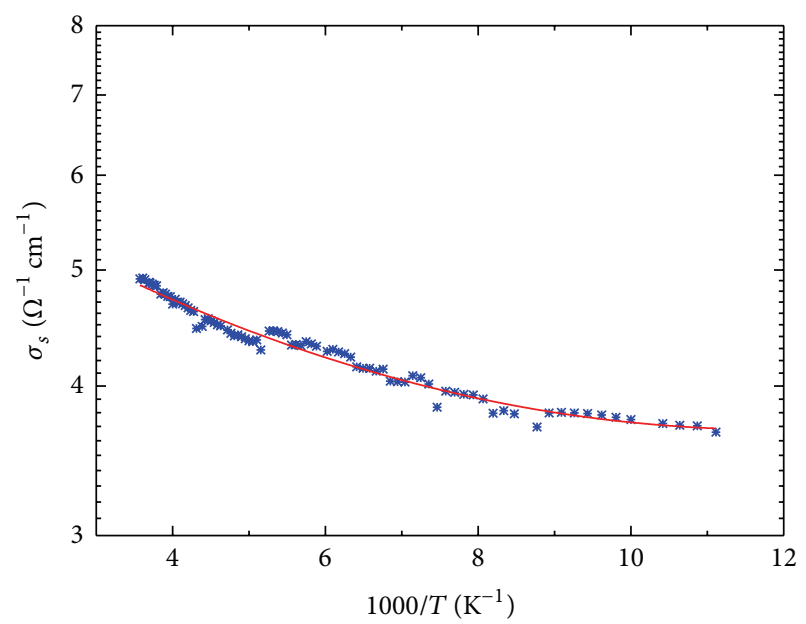

FIGURE 5: Specific conductivity depending on the temperature between $-200^{\circ} \mathrm{C}$ and RT.

To verify activation energies, temperature dependent measurements were done. In the first experiment, the specific conductivity was measured at low temperatures, as demonstrated in Figure 5. The sample with a conductivity of about $5 \mathrm{~S} / \mathrm{cm}$ at room temperature was cooled down to $-200^{\circ} \mathrm{C}$ under vacuum conditions, while the conductivity was measured.

In the second experiment, which is shown in the Arrhenius plot in Figure 6, a sample was heated up to $900^{\circ} \mathrm{C}$. This is also done under high vacuum conditions, to avoid oxidation of the diamond at temperature above $500^{\circ} \mathrm{C}$, while again the conductivity was measured.

Over the whole temperature range, from $-200^{\circ} \mathrm{C}$ to $900^{\circ} \mathrm{C}$, the specific conductivity increases, like in negative temperature coefficient thermistors. At low temperatures no freeze-out can be detected. In [8] similar measurements show even at $4.2 \mathrm{~K}$ no freeze-out, which is in contrast to conventional semiconductor definition. The slopes in the Arrhenius plot in Figure 5 indicate very low activations energies in the range of single $\mathrm{meV}$, assuming constant mobility. The nonlinearity in comparison with a non-freeze-out process indicates electronic states caused by the $\pi$ bonds of carbon in the grain boundary, which lead to the conductivity in 


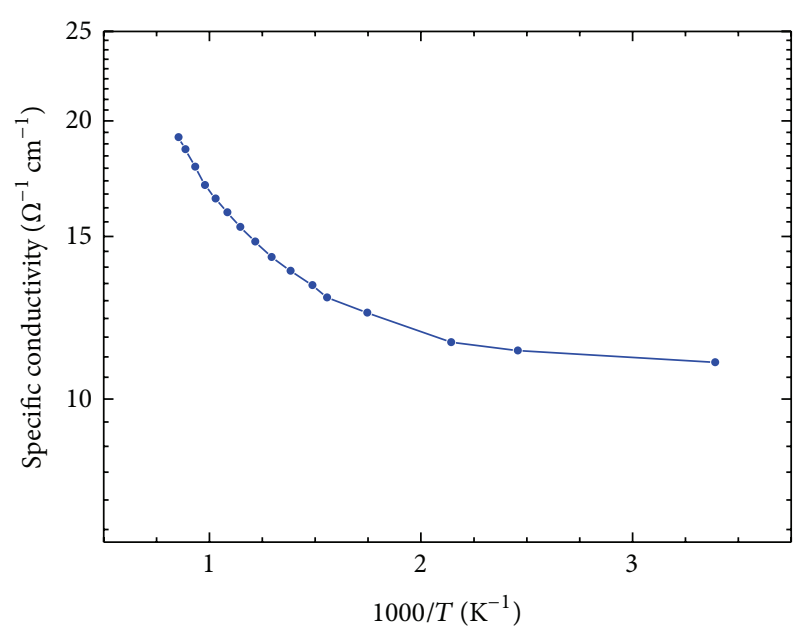

FIGURE 6: Conductivity depending on temperature between RT and $900^{\circ} \mathrm{C}$.

the diamond films. That is also assumed in several other publications $[8,11,14]$.

The high temperature measurement, shown in Figure 6, demonstrates an amazing potential over conventional semiconductors. In the temperature range from RT up to about $400^{\circ} \mathrm{C}$ the change in conductivity is lower and follows the trend of the first measurement. Above $400^{\circ} \mathrm{C}$ the conductivity increases faster. Under the same assumption, of constant mobility, the corresponding activation energies are about $50 \mathrm{meV}-150 \mathrm{meV}$. It indicates electronic states which are activated with increasing temperature but cannot be directly associated with an activation of further donors.

2.2. Metallization. To investigate electrical contacts on the UNCD surface, transmission-line-method (TLM) measurements were used. This commonly used technique [15] allows a quantitative characterization of different contact materials by the contact resistance $R_{C}$. Another good measure for the quality of the metal contact is the transfer length $L_{T}$ (which is the length under the metal contact, where the current in the film is reduced by $1 / e$, due to the currents into the metal contact). Since the contact resistance is not independent of the sheet resistance $R_{S C}$, we present also the ratio of contact resistance and sheet resistance.

For its noble character and low specific resistivity, gold is often the choice for metallization of electronic elements. On the other hand, in order to achieve good adhesion and ohmic contact behavior, it is beneficial to have a carbide forming adhesion promoter between the diamond surface and gold.

Different contact metals were tested: molybdenum, titanium, tantalum, and a titanium tungsten alloy $\left(\mathrm{Ti}_{0.8} \mathrm{~W}_{0.2}\right)$. A summary of TLM measurement results is shown in Table 1. All carbide forming metals showed ohmic behavior in the voltage range of $\pm 40 \mathrm{~V}$. Titanium and tantalum have shown significantly better electrical properties than molybdenum and the $\mathrm{Ti}_{0.8} \mathrm{~W}_{0.2}$ alloy. In [16] different types of carbides are mentioned, with their different electronegativity and atom radius. The interstitial carbide, one special type of carbide
TABLE 1: Results from TLM various measurements on CNCD samples of different conductivity.

\begin{tabular}{lcccc}
\hline Material & $R_{C}[\Omega]$ & $R_{S C}[\Omega]$ & $L_{T}[\mu \mathrm{m}]$ & $R_{C} / R_{S C} \cdot 100$ \\
\hline Mo & 402 & $18 \cdot 10^{3}$ & 4.38 & 2.21 \\
Ti & 6 & 1305 & 0.86 & 0.43 \\
Ta & 3 & 2488 & 0.28 & 0.15 \\
TiW & 1000 & $575 \cdot 10^{3}$ & 3.48 & 1.74 \\
\hline
\end{tabular}

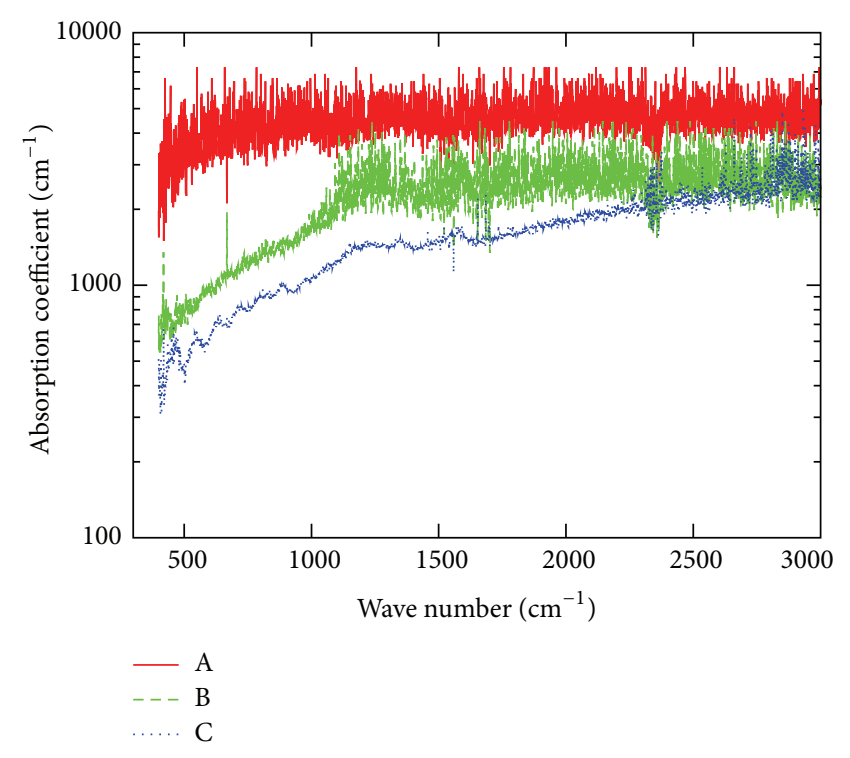

FIGURE 7: Transmission spectra.

with particularly good electrical properties, can only be found for titanium and tantalum.

Resulting from this, titanium and tantalum are suitable materials as ohmic contact material on UNCD, which was also shown for other kinds of conductive diamonds, as shown, for example, in $[17,18]$. To improve the temperature stability of the metal contact it is necessary to reduce diffusion of the titanium in gold. That can be done by a diffusion barrier between gold and titanium. Platinum is an appropriate candidate, which was also generally shown in [19]. This also leads to ohmic behavior and to a temperature stability of up to the melting point of gold.

\section{Spectroscopic Investigations}

3.1. Optical Properties. Three thick UNCD films ( $20 \mu \mathrm{m}$ thick) were grown with different $\mathrm{NH}_{3}$ concentration in the feed gas, to achieve three different conductivities.

By etching the $\mathrm{Si}$ substrate in $\mathrm{KOH}$, free standing UNCD films were obtained. They were measured by Fourier transformation infrared spectroscopy (FTIR). Assuming that Lambert-Beer's law can be applied, the absorption coefficient was calculated. The spectra are shown in Figure 7.

Sample A has a conductivity of $3.7 \mathrm{~S} / \mathrm{cm}$ at room temperature, sample B has a conductivity of $1.1 \mathrm{~S} / \mathrm{cm}$, and sample C has a conductivity of $0.16 \mathrm{mS} / \mathrm{cm}$, as measured by simple fourpoint measurements [20]. 


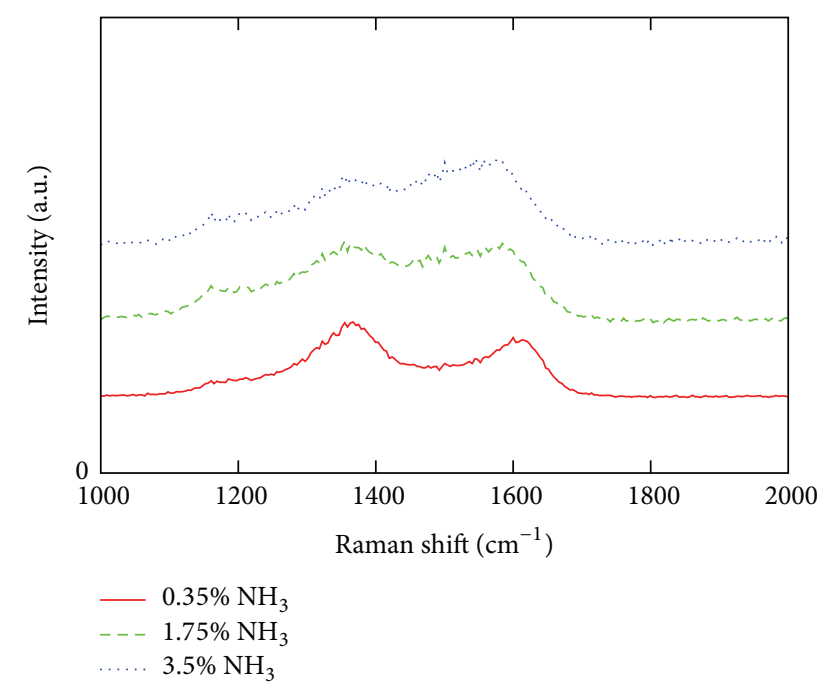

FiguRE 8: Spectra for different $\mathrm{NH}_{3}$ concentrations in the feed gas.

It can clearly be seen that, for the sample A, with the highest conductivity, nearly no transmission is found in the measured range.

The coordination of carbon atoms in grain boundaries is generally reduced [21]. Therefore $s p^{2}$ and $s p^{3}$ bonds coexist in the grain boundaries of diamond, together with impurity atoms (e.g., nitrogen). This distorted $s p^{3}$ bonds and the coexisting $s p^{2}$ bonds in the grain boundaries lead to band tailing and the appearance of $\sigma^{*}$ states (origin from distorted $s p^{3}$ bonds and dangling bonds) [14] as well as $\pi$ and $\pi^{*}$ bands (origin from $s p^{2}$ bonded carbons) [11, 14], which are responsible for the absorption at these low energies $[14,22$, 23].

We see that the absorption edge shifts to lower wave numbers (higher wave lengths) for a higher conductivity of the film. It can be concluded that the $\pi$ and $\pi^{*}$ bands are broader for samples with higher conductivity [14].

3.2. Raman Spectroscopy. Raman spectra were measured for three films that were grown with different ammonia addition. The excitation wavelength was $543 \mathrm{~nm}$. The spectra can be seen in Figure 8. A linear background was subtracted from all spectra. We can see the D-band at $1360 \mathrm{~cm}^{-1}$ and the Gband at $1560 \mathrm{~cm}^{-1}$. The diamond peak at $1333 \mathrm{~cm}^{-1}$ cannot be seen due to its smaller Raman cross section [24,25]. Therefore only the chemical constitution and structure of the grain boundaries are reflected by measurements.

The D- and G-band peaks were fitted using Lorentzian functions, revealing the intensities and full width at half maximum (FWHM) of each.

The electrical conductivities of these films were also determined by four-point measurements and these results are given in Table 2 together with the results of the Raman measurements.

Following argumentation in [25-27], the increasing FWHM of the G-band and the decreasing ratio of D-band intensity to G-band intensity $I(\mathrm{D}) / I(\mathrm{G})$ indicates an increase of structural disorder of the $s p^{2}$ bonded carbon. Therefore, we
TABLE 2: Parameters, found by fitting Lorentzian curves in the measured Raman spectra.

\begin{tabular}{lccc}
\hline $\mathrm{NH}_{3}(\%)$ & FWHM $(\mathrm{G})\left(\mathrm{cm}^{-1}\right)$ & $I(\mathrm{D}) / I(\mathrm{G})$ & $\sigma(\mathrm{S} / \mathrm{cm})$ \\
\hline 0.35 & 56.2 & 1.37 & 0.2974 \\
1.75 & 104.5 & 1.08 & 0.0113 \\
3.5 & 125.3 & 0.72 & 0.0004 \\
\hline
\end{tabular}

conclude that, for higher amount of $\mathrm{NH}_{3}$ addition to the feed gas, the disorder of the grain boundaries increases, leading to a reduction of conductivity. This relation between disorder of grain boundary and conductivity is in agreement with investigations on plasma CVD grown nitrogen doped UNCD films $[13,28]$.

\section{Summary}

We presented ultrananocrystalline diamond thin films with tuneable electrical n-type conductivity from practically isolating $\left(1 \times 10^{-3} \mathrm{~S} / \mathrm{cm}\right)$ to $200 \mathrm{~S} / \mathrm{cm}$. This conductivity is present and only varies slightly over a large temperature range $\left(-200^{\circ} \mathrm{C}\right.$ until $900^{\circ} \mathrm{C}$ was measured). A system for electrical contact metallization is shown, which is of importance for general characterization and application of the films in electrical or electromechanic devices. Our electrical measurements confirm that the conductivity is of n-type [10] and together with the spectroscopic measurements we conclude that the conductivity is due to the structure and volume of the grain boundary.

\section{Conflict of Interests}

The authors declare that there is no conflict of interests regarding the publication of this paper.

\section{Acknowledgment}

The authors gratefully acknowledge the financial support by the German ministry of education and research (BMBF) through VDI/VDE-IT, within the projects C-Hybrid (FKZ 16SV5320K) and VIP-DiM (FKZ 16SV6503).

\section{References}

[1] H. J. Fecht and M. Werner, The Nano-Micro Interface-Bridging the Micro and Nano Worlds, Wiley-VCH, 2004.

[2] H.-J. Fecht, K. Brühne, and P. Gluche, Eds., Carbon-based Nanomaterials and Hybrids-Synthesis, Properties, and Commercial Applications, Pan Stanford, Singapore, 2014.

[3] M. Werner, M. Adamschik, P. Gluche, E. Kohn, and H.-J. Fecht, "Review on diamond based piezoresistive sensors," in Proceedings of the IEEE International Symposium on Industrial Electronics (ISIE '98), vol. 1, pp. 147-152, July 1998.

[4] M. Dipalo, J. Kusterer, K. Janischowsky, and E. Kohn, "N-type doped nano-diamond in a first MEMS application," Physica Status Solidi A, vol. 203, no. 12, pp. 3036-3041, 2006.

[5] R. Kalish, "The search for donors in diamond, Diamond and Related Materials, vol. 10, no. 9-10, pp. 1749-1755, 2001. 
[6] R. Kalish, "Diamond as a unique high-tech electronic material: difficulties and prospects," Journal of Physics D: Applied Physics, vol. 40, no. 20, pp. 6467-6478, 2007.

[7] J.-P. Lagrange, A. Deneuville, and E. Gheeraert, "Activation energy in low compensated homoepitaxial boron-doped diamond films," Diamond and Related Materials, vol. 7, no. 9, pp. 1390-1393, 1998.

[8] S. Bhattacharyya, O. Auciello, J. Birrell et al., "Synthesis and characterization of highly-conducting nitrogen-doped ultrananocrystalline diamond films," Applied Physics Letters, vol. 79, no. 10, pp. 1441-1443, 2001.

[9] O. A. Williams, S. Curat, J. E. Gerbi, D. M. Gruen und, and R. B. Jackman, " $n$-type conductivity in ultrananocrystalline diamond films," Applied Physics Letters, vol. 85, no. 10, pp. 1680-1682, 2004.

[10] N. Wiora, M. Mertens, M. Mohr, K. Brühne, and H.-J. Fecht, "Synthesis and characterization of n-type nitrogenated nanocrystalline diamond," Micromaterials and Nanomaterials, vol. 15, no. 96-98, pp. 1619-2486, 2013.

[11] P. Zapol, M. Sternberg, L. A. Curtis, T. Frauenheim, and D. M. Gruen, "Tight-binding molecular-dynamics simulation of impurities in ultrananocrystalline diamond grain boundaries," Physical Review B-Condensed Matter and Materials Physics, vol. 65, no. 4, Article ID 045403, 2001.

[12] J. Birrell, J. A. Carlisle, O. Auciello, D. M. Gruen, and J. M. Gibson, "Morphology and electronic structure in nitrogendoped ultrananocrystalline diamond," Applied Physics Letters, vol. 81, no. 12, pp. 2235-2237, 2002.

[13] T. Ikeda, K. Teii, C. Casiraghi, J. Robertson, and A. C. Ferrari, "Effect of the $s p^{2}$ carbon phase on $n$-type conduction in nanodiamond films," Journal of Applied Physics, vol. 104, no. 7, Article ID 073720, 2008.

[14] P. Achatz, J. A. Garrido, M. Stutzmann et al., "Optical properties of nanocrystalline diamond thin films," Applied Physics Letters, vol. 88, no. 10, Article ID 101908, 2006.

[15] G. K. Reeves and H. B. Harrison, "Obtaining the specific contact resistance from transmission line model measurements," IEEE Electron Device Letters, vol. 3, no. 5, pp. 111-113, 1982.

[16] H. O. Pierson, Handbook of Refractory Carbides and Nitrides, Noyes Publications, 1996.

[17] K. Das, V. Venkatesan, K. Miyata, D. L. Dreifus, and J. T. Glass, "A review of the electrical characteristics of metal contacts on diamond," Thin Solid Films, vol. 212, no. 1-2, pp. 19-24, 1992.

[18] K. Das, V. Venkatesan, K. Miyata, D. L. Dreifus, and J. T. Glass, "A review of the electrical characteristics of metal contacts on diamond," Thin Solid Films, vol. 212, no. 1-2, pp. 19-24, 1992.

[19] T. C. Tisone and J. Drobek, "Diffusion in thin film Ti-Au, Ti-Pd, and Ti-Pt couples," Journal of Vacuum Science and Technology, vol. 9, no. 1, pp. 271-275, 1972.

[20] L. Valdes, "Resistivity measurements on germanium for transistors," Proceedings of the IRE, vol. 42, no. 2, pp. 420-427, 1954.

[21] P. Keblinski, D. Wolf, S. R. Phillpot, and H. Gleiter, "Role of bonding and coordination in the atomic structure and energy of diamond and silicon grain boundaries," Journal of Materials Research, vol. 13, no. 8, pp. 2077-2099, 1998.

[22] O. A. Williams, "Nanocrystalline diamond," Diamond and Related Materials, vol. 20, no. 5-6, pp. 621-640, 2011.

[23] M. Nesládek, K. Meykens, L. M. Stals, M. Vaněček, and J. Rosa, "Origin of characteristic subgap optical absorption in CVD diamond films," Physical Review B, vol. 54, no. 8, pp. 5552-5561, 1996.
[24] S. R. Sails, D. J. Gardiner, M. Bowden, J. Savage, and D. Rodway, "Monitoring the quality of diamond films using Raman spectra excited at $514.5 \mathrm{~nm}$ and $633 \mathrm{~nm}$," Diamond and Related Materials, vol. 5, no. 6-8, pp. 589-591, 1996.

[25] F. Klauser, D. Steinmüller-Nethl, R. Kaindl, E. Bertel, and N. Memmel, "Raman studies of nano-and ultra-nanocrystalline diamond films grown by hot-filament CVD," Chemical Vapor Deposition, vol. 16, no. 4-6, pp. 127-135, 2010.

[26] A. C. Ferrari and J. Robertson, "Raman spectroscopy of amorphous, nanostructured, diamond-like carbon, and nanodiamond," Philosophical Transactions of the Royal Society A, vol. 362, no. 1824, pp. 2477-2512, 2004.

[27] A. C. Ferrari and J. Robertson, "Origin of the $1150 \mathrm{~cm}-1$ Raman mode in nanocrystalline diamond," Physical Review B: Condensed Matter and Materials Physics, vol. 63, no. 12, Article ID 121405, 2001.

[28] J. Birrell, J. E. Gerbi, O. Auciello, J. M. Gibson, D. M. Gruen, and J. A. Carlisle, "Bonding structure in nitrogen doped ultrananocrystalline diamond," Journal of Applied Physics, vol. 93, no. 9, pp. 5606-5612, 2003. 

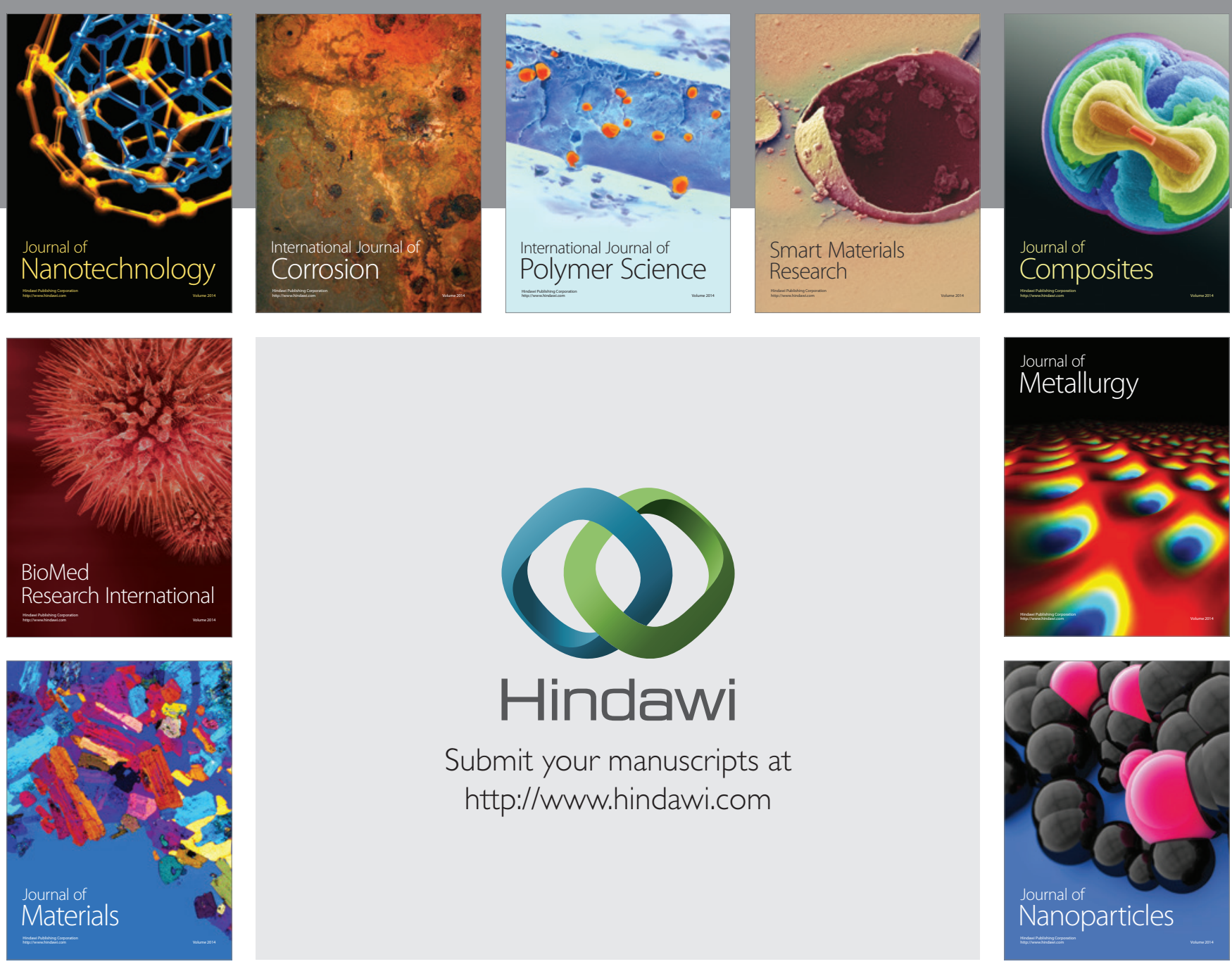

Submit your manuscripts at http://www.hindawi.com
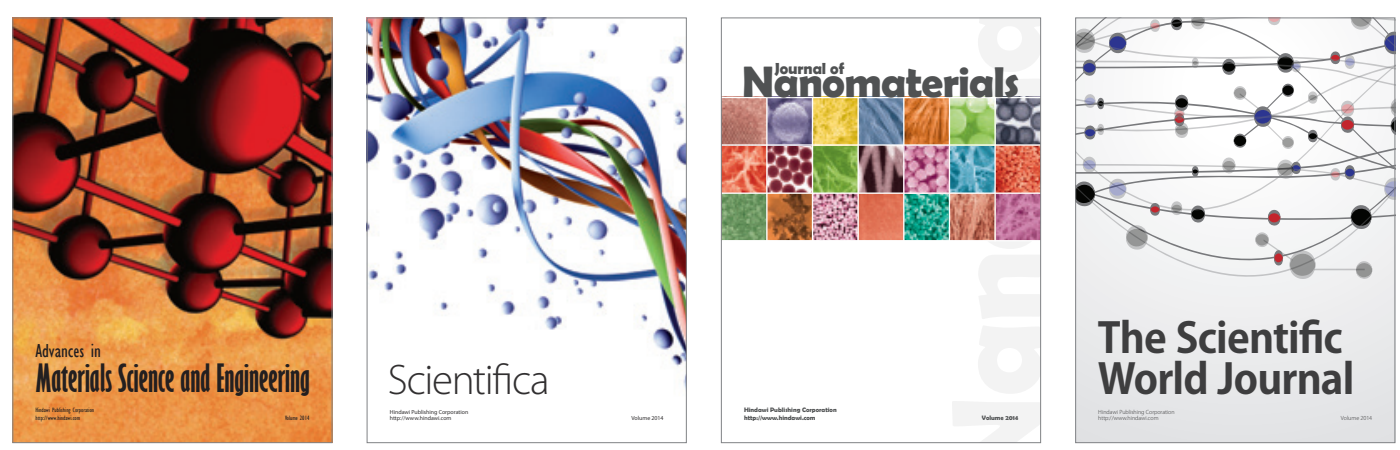

\section{The Scientific World Journal}
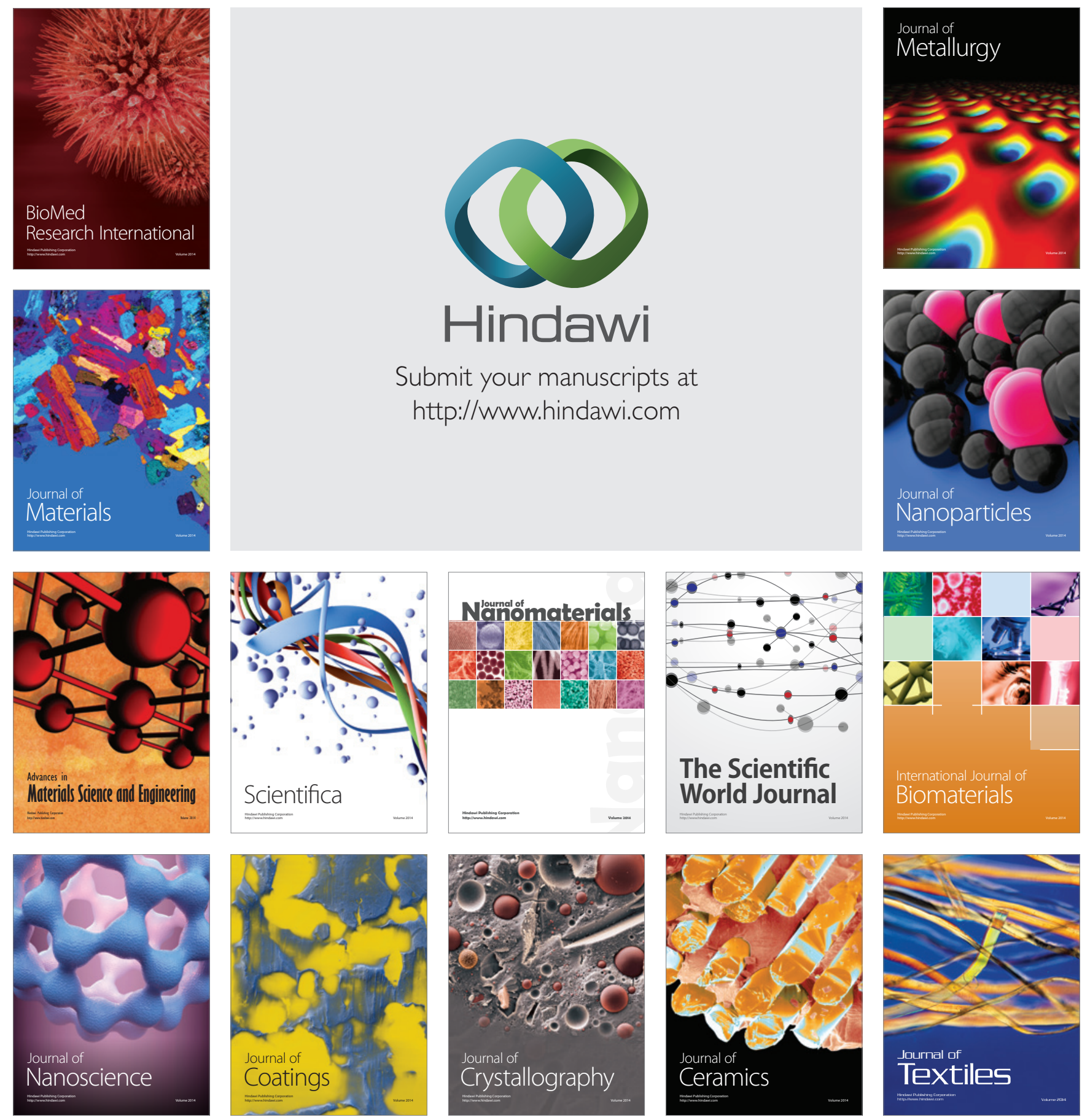